\title{
The Enhancing Effect of a Triethanolamine-Ethanol-Isopropyl Myristate Mixed System on the Skin Permeation of Acidic Drugs
}

\author{
Liang Fang, ${ }^{a}$ Yoichi Kobayashi, ${ }^{b}$ Sachihiko Numajiri, ${ }^{a}$ Daisuke Kobayashi, ${ }^{a}$ Kenji Sugibayashi,,${ }^{a}$ and \\ Yasunori MORIMOTO*,a \\ ${ }^{a}$ Faculty of Pharmaceutial Sciences, Josai University; 1-1 Keyakidai, Sakado, Saitama 350-0295, Japan: and ${ }^{b}$ Toko \\ Pharmaceutical Ind. Co., Ltd.; 3-3-19 Shinden, Adachi-ku, Tokyo 123-0865, Japan. \\ Received April 8, 2002; accepted July 3, 2002
}

The effect of a TEI enhancer mixed system consisting of triethanolamine (T), ethanol (E) and isopropyl myristate (IPM) on the skin permeation of acidic, basic and neutral drugs were evaluated in vitro using excised hairless rat skin. The binary enhancer system consisting of IPM and ethanol (EI) produced marked improvement on the penetration of all the drugs tested. When $T$ was added to the EI system, a greater enhancing effect was found only on acidic drugs with a carboxyl group, compared with the flux in the EI system. On addition of another amine to the EI system, instead of T, mefenamic acid (MA), which exhibited the highest enhancing effect of the model drugs, showed an approximately 14-180 times greater flux than when delivered by the EI system. On simultaneous application of isosorbide dinitrate (ISDN) with MA in the TEI system, the flux of MA increased on increasing the T concentration in the TEI system, while, the flux of ISDN, a neutral drug, was unaffected by the $T$ concentration. Application of MA in the EI system after pretreatment of the TEI system showed that the residual amount of $T$ in the skin plays an important role in the skin permeation of MA. Furthermore, at a fixed concentration of MA, the flux of MA increased on increasing the $T$ concentration in the TEI system, while the flux of $E$ remained unchanged. Finally, the infrared spectrum of MA with amine in the $E$ solution indicated that the carboxyl group of MA was ionized. These results demonstrated that the formation of an ion pair between MA and T, but not the effect of $T$ on the skin, may be responsible for the enhanced skin permeation of MA using the TEI system.

Key words lipophilic multiconponent system; acidic drug; ion pair; triethanolamine; ethanol; isopropyl myristate

Although the transdermal drug delivery system, used as non-oral alternative systemic drug delivery system, is a convenient system form for primary and intensive home care (since it does not involve direct injection through the skin), the skin barrier prevents the passage of most drugs. To overcome the skin barrier function temporarily, various physical (iontophoresis, ultrasound, electoporation) and chemical (penetration enhancers, prodrugs) method or their combinations have been used to achieve enhanced transdermal drug transport. ${ }^{1)}$ Among these methods, the most widely used to enhance permeation of stratum corneum barrier are the chemical penetration enhancers. ${ }^{2)}$ Despite the large amount of research and the many different chemical enhancers identified, few have yet reached the market place, because in most of cases, there is a linear correlation between the enhancement effects and skin toxicity. ${ }^{3)}$ This has stimulated research into the combined use of two or more safe and known types of additives. ${ }^{4-6)}$ We have reported a greatly increased effect of $l$-menthol-ethanol-water (MEW) system on the skin permeation of morphine and several cardiovascular agents compared with their use as single agents. ${ }^{7,8)}$ The MEW system has a non-selective enhancing effect on a range of both hydrophilic and hydrophobic drugs, and this unselective effect is due to the delipidation of the stratum corneum. This produces skin irritation. ${ }^{9)}$ This result suggests that, if a drug-selective enhancer can be found, it should be possible to minimize the skin irritation. We have found that a lipophilic multicomponent system consisted of L-lactic acid (1\%), ethanol $(10 \%)$ and isopropyl myristate (LEI) system selectively enhances the skin permeation of basic drugs and causes very little skin irritation. ${ }^{10-12)}$ On the other hand, there are many acidic drugs such as NSAIDs which are potentially effective and used routinely in clinical situations. Therefore, it is worthwhile developing a skin permeation enhancer, which would be selective for acidic drugs. In the present study, we have studied a lipophilic multicomponent system consisted of triethanolamine, ethanol and isopropyl myristate (TEI) system, based on our earlier LEI system.

\section{MATERIALS AND METHODS}

Materials Mefenamic acid (MA), monoethanolamine (M), diethanolamine (D), triethanolamine (T) diethylamine (De), triethylamine (Te), propanolamine (P) and aminopyrine, were purchased from Wako Pure Chemical Ind., Ltd. (Osaka, Japan). Ketoprofen was supplied by Nissan Chemical Ind., Ltd. (Tokyo, Japan). Isosorbide dinitrate (ISDN) was supplied by Toko Pharmaceutical Ind. Co., Ltd. (Tokyo, Japan). Ibuprofen and ketotifen fumarate were obtained from Nissei Chemical Co., Ltd. (Tokyo, Japan). Diclofenac sodium, antipyrine and isopropyl myristate (IPM) were obtained from Tokyo Kasei Kogyo Co., Ltd. (Tokyo, Japan). Dehydrated ethanol (E) (JP grade) was purchased from Imazu Yakuhin Kogyo K. K. (Tokyo, Japan). All other chemicals and solvents were of reagent grade.

Animals Male hairless rats (WBN/ILA-Ht) weighting $180-220 \mathrm{~g}$ (6-8 weeks old) used in all experiments were supplied by Life Science Research Center of Josai University (Saitama, Japan). The experiments were performed in accordance with the guidelines for animal use in the Life Science Research Center of Josai University.

Preparation of Diclofenac Acid Diclofenac acid was prepared from diclofenac sodium by acid precipitation. Twenty grams of diclofenac sodium was dissolved in 21 dis- 
tilled water and stirred well while protecting it from light. Ten milliliters of $1 \mathrm{~m} \mathrm{HCl}$ solution was added dropwise with stirring and the free acid was extracted into chloroform. The chloroform extracts was dried over anhydrous sodium sulfate, then evaporated to dryness under reduced pressure using a rotary evaporator. The residue was dried under reduced pressure. Infrared spectroscopy and measurement of melting point were used to confirm the identification of diclofenac acid by comparison with reported data. ${ }^{13)}$

In Vitro Permeation Procedure The skin permeation experiment was carried out according to the method described in the previous report. ${ }^{14)} \mathrm{A}$ side-by-side (2-chamber) diffusion cell was used for in vitro permeation experiment. Each cell has a volume of $2.5 \mathrm{ml}$ and an effective diffusion area of $0.95 \mathrm{~cm}^{2}$. A star-head bar in each cell was driven by a constant-speed synchronous motor (MC-301, Scinics, Tokyo) at about $600 \mathrm{rpm}$. The hairless rats were anesthetized with sodium pentobarbital $\left(500 \mathrm{mg} \mathrm{kg}^{-1}\right.$, i.p.) and the abdomen was carefully shaved. About $5 \mathrm{~cm}^{2}$ (circle of $2.5 \mathrm{~cm}$ diameter) of skin on the left and right sides of the abdomen was excised and the skin membrane was checked to ensure that no obvious defects were present, then it was immediately mounted between two diffusion cells using a spring clamp. The cell sets were connected to a water bath at $32^{\circ} \mathrm{C}$. The dermis and stratum corneum of the skin was in contact with the receiver and the donor compartment, respectively. The receiver compartment of each cell was filled with $2.5 \mathrm{ml}$ of distilled water and the donor compartment with $2.5 \mathrm{ml}$ of drug suspension (about twice the solubility) or solution in each solvent system. Sample solution was withdrawn periodically from the receiver side chamber, and a similar volume of distilled water was added to keep the volume constant. The donor solution was replaced every $1 \mathrm{~h}$ to avoid a reduction in the drug thermodynamic activity and a change in vehicle components in the system throughout the experiment. Each experiment was carried out for $8 \mathrm{~h}$ to achieve a steady permeation rate.

Pretreatment Permeation Study The skin membrane was mounted between 2-chamber diffusion cells, and the TEI system was applied to the stratum corneum side for $4 \mathrm{~h}$. At the end of the treatment period, the donor solution was removed carefully, followed by rinsing three times with the EI system. At this time, the MA suspension in the EI system and water was added to the donor and the receiver compartments, respectively, then the permeation study was performed for the next $8 \mathrm{~h}$. Samples were collected from the receiver side was every hour.

Determination of Drug Solubility The solubility of each drug in various vehicles was determined. The vehicles were water, ethanol, IPM, the EI and TEI system. Each drug was added to the vehicles in excess of its solubility. The suspensions were agitated in a water bath at $32^{\circ} \mathrm{C}$ for $24 \mathrm{~h}$. The amount of each drug in the vehicles was determined by HPLC after centrifugation and appropriate dilution with ethanol or acetonitrile. Experiment was performed in triplicate.

Fourier Transform Infrared Spectroscopy in Ethanol Solution The infrared spectra of the samples $(7.5 \mu \mathrm{mol} / \mathrm{ml}$ $\mathrm{MA}$ and $7.5-150 \mu \mathrm{mol} / \mathrm{ml}$ alkanolamine in ethanol) were obtained on a JASCO FT/IR 5300 spectrometer using an infrared spectrophotometer cell (SL-Ge air-tight cell, GL Sci- ences, Tokyo) in the region $4000-400 \mathrm{~cm}^{-1}$.

Analytical Method Each drug was determined by HPLC. The HPLC system consisted of an LC-10AS pump, a SIL-10A $\mathrm{XL}_{\mathrm{XL}}$ auto injector, a SPD-10A variable-wavelength ultraviolet absorbance detector, and a CTO-10A column oven (all from Shimadzu Seisakusho, Kyoto, Japan). A micro-data processor (C-R5A Chromatopac, Shimadzu) was used for peak-area integration and calculations. Analysis was performed on a $5 \mu \mathrm{m}$ LiChrospher ${ }^{\circledR} 100 \mathrm{RP}-18 \mathrm{e}$ reversed-phase column $(250 \times 4.6 \mathrm{~mm}$ i.d., Cica-MERCK, Darmastadt), operated at $40{ }^{\circ} \mathrm{C}$. The other conditions such as composition of mobile phase, flow rate, internal standard and wavelength were as described previously in the literature. ${ }^{12,15)}$ Calibration curves were constructed using peak area measurements.

The amount of ethanol in receptor fluids was determined by gas chromatography using a system with an AOC-17 auto injector and a flame ionization detector (GC-14A gas chromatography, Shimadzu Seisakusho, Kyoto). The conditions were: injection volume, $1 \mu \mathrm{l}$; column, Gaskuropack 54 (60/80 mesh, GL science, Tokyo); the injection port, column oven and detector port were maintained at $200,160,200^{\circ} \mathrm{C}$, respectively; Nitrogen was used as the carrier gas at carrier pressure $1 \mathrm{~kg} / \mathrm{cm}^{2}$. 2-propanol was used as an internal standard. The retention time of ethanol was $3.95 \mathrm{~min}$. The detection limit was $0.1 \mathrm{mg} / \mathrm{ml}(\mathrm{CV}, 4.2 \%)$.

The amount of $\mathrm{T}$ in receptor fluids was also assayed by gas chromatography using a system with an AOC-17 auto injector and a flame ionization detector (GC-14A gas chromatography, Shimadzu Seisakusho, Kyoto). ${ }^{16)}$ The conditions were: injection volume, $1 \mu \mathrm{l}$; column, TC-WAX capillary column $(0.53 \mathrm{~mm}$ i.d. $\times 15 \mathrm{M}, \mathrm{df}=1.0 \mu \mathrm{m}, \mathrm{GL}$ Science, Tokyo); the injection port, column oven and detector port were maintained at $300,220,300^{\circ} \mathrm{C}$, respectively; the flow-rate of carrier and make up carrier gas (Nitrogen) was 8.0 and $30.0 \mathrm{ml} / \mathrm{min}$, respectively. The absolute calibration method was used. The retention time of $\mathrm{T}$ was $4.6 \mathrm{~min}$. The detection limit was 0.1 $\mathrm{mg} / \mathrm{ml}$ (CV, 2.3\%).

Data Analysis The amount of each drug permeating through the epidermis during a sampling interval was calculated based on the measured receptor-phase concentration and volume. The cumulative amount of drug permeating per unit area $v s$. time was plotted. The flux $(J)$ was calculated from the slope of the linear portion of the plot. The permeability coefficient $(P)$ was obtained by dividing $J$ by the initial drug concentration in the donor phase.

For the pretreatment permeation study, $\mathrm{T}$ content per unit area of the skin was calculated according to the equation bellow:

$\mathrm{T}$ content per unit area
$=($ Cumulative amount of $\mathrm{T}$ over $8 \mathrm{~h}$
$\quad$ - Cumulative amount of $\mathrm{T}$ at each sampling time point)/area

\section{RESULTS}

Effect of the TEI System on the Skin Permeation of Drug The steady-state flux $(J)$ and permeability coefficient $(P)$ of each drug from the IPM, EI and TEI systems are presented in Table 1. As can be seen from the data in column 4 and 5 of Table 1, each drug flux in the EI system is greater than that from IPM (from 2.8 times for ketoprofen to 817 
Table 1. The Flux and Permeability Coefficient of Several Drugs in Various Vehicles through Hairless Rat Skin

\begin{tabular}{|c|c|c|c|c|c|}
\hline Drug & Acid/base & & IPM & EI system & TEI system \\
\hline \multirow[t]{2}{*}{ Ibuprofen } & Acid & $J^{a)}$ & $0.72 \pm 0.03$ & $2.21 \pm 0.16$ & $2.34 \pm 0.32$ \\
\hline & & $P^{b)}$ & $2.4 \times 10^{-7}$ & $4.2 \times 10^{-7}$ & $4.4 \times 10^{-7}$ \\
\hline \multirow[t]{2}{*}{ Mefenamic acid } & Acid & $J$ & $0.007 \pm 0.002$ & $0.029 \pm 0.002$ & $0.78 \pm 0.20$ \\
\hline & & $P$ & $1.6 \times 10^{-7}$ & $1.7 \times 10^{-7}$ & $4.3 \times 10^{-6}$ \\
\hline \multirow[t]{2}{*}{ Diclofenac acid } & Acid & $J$ & $0.005 \pm 0.0003$ & $0.08 \pm 0.002$ & $0.88 \pm 0.11$ \\
\hline & & $P$ & $6.8 \times 10^{-8}$ & $2.3 \times 10^{-7}$ & $2.2 \pm 10^{-6}$ \\
\hline \multirow[t]{2}{*}{ Ketoprofen } & Acid & $J$ & $0.12 \pm 0.002$ & $0.33 \pm 0.02$ & $2.62 \pm 0.06$ \\
\hline & & $P$ & $4.8 \times 10^{-7}$ & $8.8 \times 10^{-7}$ & $6.9 \times 10^{-6}$ \\
\hline \multirow[t]{2}{*}{ Aminopyrine } & Base & $J$ & $0.86 \pm 0.12$ & $48.9 \pm 6.05$ & $26.0 \pm 4.32$ \\
\hline & & $P$ & $2.3 \times 10^{-6}$ & $6.0 \times 10^{-5}$ & $6.0 \times 10^{-5}$ \\
\hline \multirow[t]{2}{*}{ Antipyrine } & Base & $J$ & $1.23 \pm 0.09$ & $58.9 \pm 2.23$ & $50.4 \pm 1.70$ \\
\hline & & $P$ & $8.8 \times 10^{-6}$ & $7.1 \times 10^{-5}$ & $4.9 \times 10^{-5}$ \\
\hline \multirow[t]{2}{*}{ Ketotifen fumarate } & Base & $J$ & $0.006 \pm 0.0005$ & $4.8 \pm 0.29$ & $0.47 \pm 0.34$ \\
\hline & & $P$ & $7.3 \times 10^{-6}$ & $6.6 \times 10^{-4}$ & $1.1 \times 10^{-5}$ \\
\hline \multirow[t]{2}{*}{ Isosorbide dinitrate } & - & $J$ & $0.09 \pm 0.008$ & $0.91 \pm 0.04$ & $0.91 \pm 0.11$ \\
\hline & & $P$ & $2.6 \times 10^{-7}$ & $2.3 \times 10^{-6}$ & $1.7 \times 10^{-6}$ \\
\hline
\end{tabular}

a) $J:$ flux $\left(\mu \mathrm{mol} / \mathrm{cm}^{2} / \mathrm{h}\right)$, b) $P:$ permeability coefficient $(\mathrm{cm} / \mathrm{s})$. Each value represents the mean \pm S.E. of three permeation experiments.

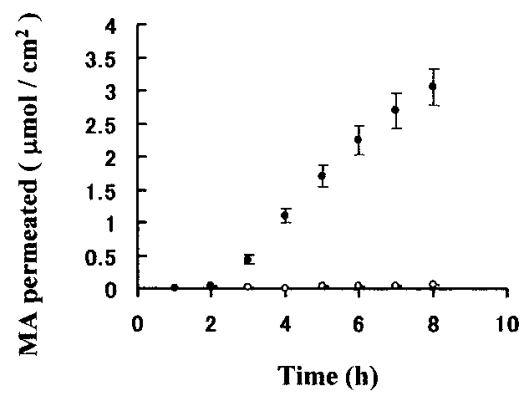

Fig. 1. In Vitro Permeation Profiles of Mefenamic Acid through Excised Hairless Rat Skin from the EI (open symbol) and TEI (closed symbol) Systems at $32{ }^{\circ} \mathrm{C}$

Each point represents the mean \pm S.E. of three permeation experiments.

times for ketotifen fumarate). It is worth noting that the flux in the TEI system is greater than that in the EI system for acidic drugs with carboxyl group, except for ibuprofen. In particular, the flux of MA is increased 27 -fold by addition of $\mathrm{T}$ to the EI system (Fig. 1). On the other hand, as we would expect, the fluxes of basic drug (aminopyrine and antipyrine) and neutral drug (ISDN) are almost unchanged in the TEI system, within experimental error, while the flux of ketotifen fumarate in the TEI system significantly decreased compared with that in the EI system. These results clearly show that the TEI system can selectively enhance the skin permeation of acidic drugs.

Effect of Other Amines on the Skin Permeation Enhancement of MA Since the acidic drug permeation was enhanced by addition of $\mathrm{T}$ to the EI system, we investigated the effectiveness of other amines. We selected MA, as a model permeant, which exhibited the highest enhancement by the TEI system and conducted another permeation study. Equimolar amount of amines (D, M, P, De, Te) in the EI system instead of $T$, were used to produce the new enhancer system. Table 2 summarizes the flux and permeability coefficient of MA from each system. An enhancing effect was observed for each amine, and the rank order of MA permeability coefficient from each system was TeEI $>$ DeEI $>$ MEI $>$ PEI $>$ TEI $>$ DEI $>$ EI. This is nearly in accordance with the rank order of the $\mathrm{p} K_{\mathrm{a}}$ of each amine. Comparison of the en-
Table 2. The Flux and Permeability Coefficient of Mefenamic Acid in the Amine-EI System through Hairless Rat Skin and the $\mathrm{p} K_{\mathrm{a}}$ of Amines Used in this Study

\begin{tabular}{lccc}
\hline \hline System & $\mathrm{p} K_{\mathrm{a}}$ & $J\left(\mu \mathrm{mol} / \mathrm{cm}^{2} / \mathrm{h}\right)$ & $P \times 10^{-7}(\mathrm{~cm} / \mathrm{s})$ \\
\hline EI & - & $0.029 \pm 0.02$ & $2.05 \pm 0.51$ \\
DEI & $9.00^{a)}$ & $0.41 \pm 0.05$ & $31.3 \pm 3.9$ \\
TEI & $7.65^{b)}$ & $0.78 \pm 0.20$ & $61.1 \pm 14.2$ \\
PEI & $10.16^{c)}$ & $4.18 \pm 0.11$ & $201 \pm 5.2$ \\
MEI & $9.50^{d)}$ & $5.29 \pm 0.12$ & $275 \pm 6.2$ \\
DeEI & $10.98^{e)}$ & $1.03 \pm 0.11$ & $947 \pm 99$ \\
TeEI & $10.67^{e)}$ & $2.18 \pm 0.16$ & $1462 \pm 112$ \\
\hline
\end{tabular}

a) Bjerrum J., Chem. Rev., 46, 381 (1950). b) Geissman T. A., et al., J. Am. Chem. Soc., 76, 4182 (1954). c) Alner D. J., et al., J. Chem. Soc. (A), 417 (1968). d) Bates R. G., et al., J. Research Natl. Bur. Standards, 46, 349 (1951). e) Fyfe W. S., et al., J. Chem. Soc., 77, 1347 (1955). Each data represents the mean \pm S.E. of three experiments.

hancement potency for the amine-EI system allowed us to conclude that the enhancement effect is common to amines and dependent on the amine basicity.

Then, to investigate the enhancing effect of amine, it was decided to select $\mathrm{T}$ for the following investigation. There are several reasons for selecting T. Firstly, T is widely used in excipients for injection solution and a recent clinical study demonstrated that $\mathrm{T}$ appeared to be generally free of any irritating effect below a concentration of 5\%. ${ }^{17-20)}$ Secondly, Te, De, $\mathrm{P}, \mathrm{D}$ and $\mathrm{M}$ are more irritant than $\mathrm{T}$, and it is possible that these amines may damage the stratum corneum of the skin. Consequently, these amines are not ideally suited for investigating the enhancing mechanism, although the TeEI, DeEI, MEI and PEI system have a strong enhancing effect on skin permeation of MA.

Permeation Study of MA with ISDN To examine the role of $\mathrm{T}$ in the TEI system, it was decided to conduct a permeation study of MA with ISDN, a non-ionic and neutral drug. MA and ISDN dissolved in the TEI system were applied to donor chamber and the cumulative amount of both permeants was measured. In this permeation study, the $\mathrm{T}$ concentration in the TEI system covered the range 0 to $0.025 \mathrm{mmol} / \mathrm{ml}$. As can be clearly seen from Fig. 2, the MA flux increase on increasing the $\mathrm{T}$ concentration in the TEI system, unlike the ISDN flux is not influenced by the $\mathrm{T}$ con- 

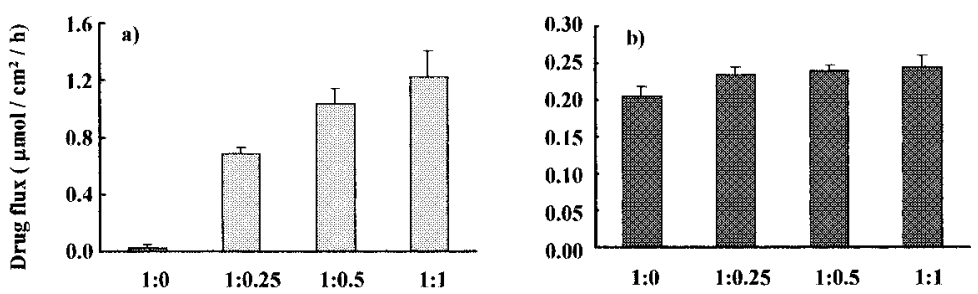

MA : T

Fig. 2. Effect of Triethanolamine Concentration in the TEI System on the Flux of Mefenamic Acid (a) and Isosorbide Dinitrate (b) through Hairless Rat Skin

Each column represents the mean \pm S.E. of three permeation experiments.

Table 3. The Molecular Weight and Solubility of Drugs in Various Vehicles

\begin{tabular}{lccccc}
\hline \hline \multirow{2}{*}{\multicolumn{1}{c}{ Drug }} & & \multicolumn{4}{c}{ Solubility $(\mathrm{mg} / \mathrm{ml})$} \\
\cline { 3 - 6 } & & $\mathrm{MW}^{a)}$ & \\
\cline { 3 - 6 } & & Ethanol & IPM & $\mathrm{EI}^{b)}$ & TEI $^{c)}$ \\
\hline Ibuprofen & 206.27 & 474.2 & 172.6 & 302.0 & 305.3 \\
Mefenamic acid & 241.29 & 14.13 & 2.96 & 11.39 & 12.07 \\
Diclofenac acid & 296.15 & 49.72 & 5.59 & 28.87 & 28.66 \\
Ketoprofen & 254.28 & 541.6 & 17.10 & 26.39 & 26.70 \\
Aminopyrine & 231.29 & 370.7 & 24.03 & 52.96 & 28.13 \\
Antipyrine & 188.23 & 350.4 & 7.35 & 43.72 & 53.47 \\
Ketotifen fumarate & 425.50 & 7.38 & 0.1 & 0.86 & 4.94 \\
Isosorbide dinitrate & 236.14 & 29.32 & 23.67 & 26.22 & 35.67 \\
\hline
\end{tabular}

a) MW: molecular weight, $b$ ) EI: EI system, $c$ ) TEI: TEI system.

centration. This result suggests that the enhancing effect of the TEI system is not caused by a reduction in the skin barrier function.

Solubility of Each Drug in Various Vehicles To evaluate the relationship between the enhancing effect of the EI or TEI system and solubility, the solubility of each drug in various donor vehicles was determined. Table 3 summarizes the molecular weight (MW) and solubility in each vehicle of eight drugs used in this experiment. As can be seen from the data in column 4 and 5 of Table 3 , the solubility of each drug in the EI system is higher than that in IPM, except for ISDN. However, there is no difference in the solubility of the acidic drugs in the TEI system and EI systems. This suggests that the significant enhancing effect on acidic drugs cannot be explained by the solubility of each drug.

Pretreatment Permeation Study We investigated the interaction of $\mathrm{T}$ and MA, because it is difficult to explain the significant enhancing effect of the TEI system by a reduction in the barrier function of the stratum corneum by enhancer system or solubility in donor solution. Figure 3 shows the time-course of the flux of MA and the residual amount of T in the skin when MA suspension in the EI system was applied after pretreatment with the TEI system. The MA flux was correspondingly reduced on reducing the amount of $\mathrm{T}$ in the skin. This suggests that the residual amount of $\mathrm{T}$ in the skin plays an important role in the skin permeation of MA.

Effect of T Concentration in the TEI System on the Skin Permeation of MA Next, we investigated the relationship between the MA permeation and the permeation behavior of $\mathrm{T}$ and $\mathrm{E}$. We determined the permeated amount of $\mathrm{MA}, \mathrm{T}$, and $\mathrm{E}$, when the $\mathrm{T}$ concentration in the TEI system ranged from 0 to $0.25 \mathrm{mmol} / \mathrm{ml}$ with a fixed MA concentra-
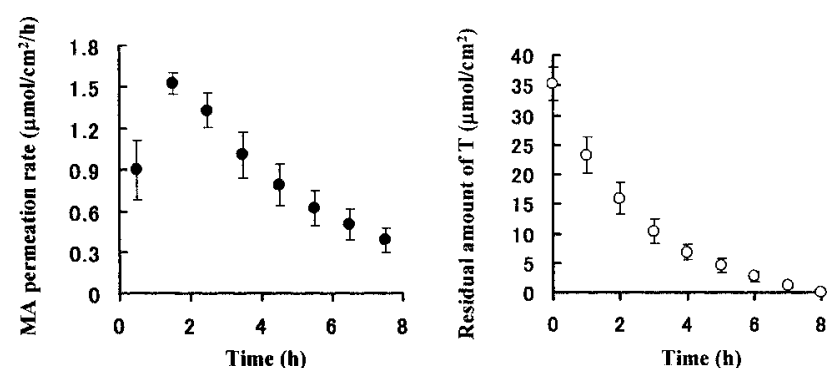

Fig. 3. Flux of Mefenamic Acid through Hairless Rat Skin in the EI System and the Residual Amount of Triethanolamie in the Skin after a 4-h Pretreatment of the TEI System

Each point represents the mean \pm S.E. of four permeation experiments.
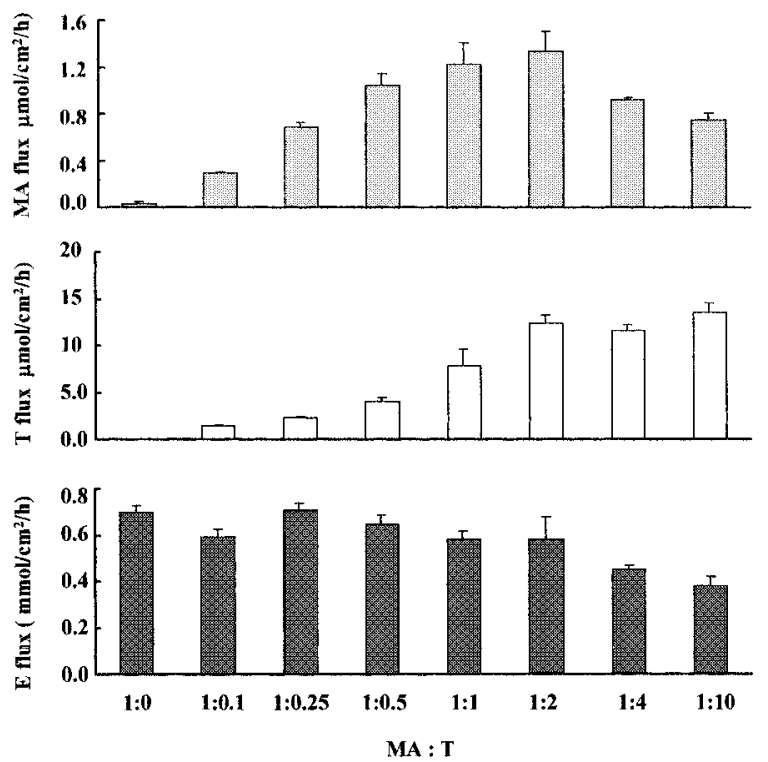

Fig. 4. Effect of Triethanolamine Concentration in the TEI System on the Fluxes of MA, T, E through Hairless Rat Skin

Each column represents the mean \pm S.E. of three permeation experiments.

tion of $0.025 \mathrm{mmol} / \mathrm{ml}$. The fluxes of MA, T and E are presented in Fig. 4. The flux of MA increased on increasing the $T$ concentration in the TEI system up to molar ratio of MA: $\mathrm{T}=1: 2$. However, beyond this concentration, the flux did not increase with a further increase in the concentration of $\mathrm{T}$. At the same time, the flux of $\mathrm{T}$ increased on increasing the $\mathrm{T}$ concentration in the TEI system up to a molar ratio MA: $\mathrm{T}=1: 2$, while, the flux of $\mathrm{T}$ did not increase with a further increase in the concentration of $\mathrm{T}$. In contrast, the flux of $\mathrm{E}$ 


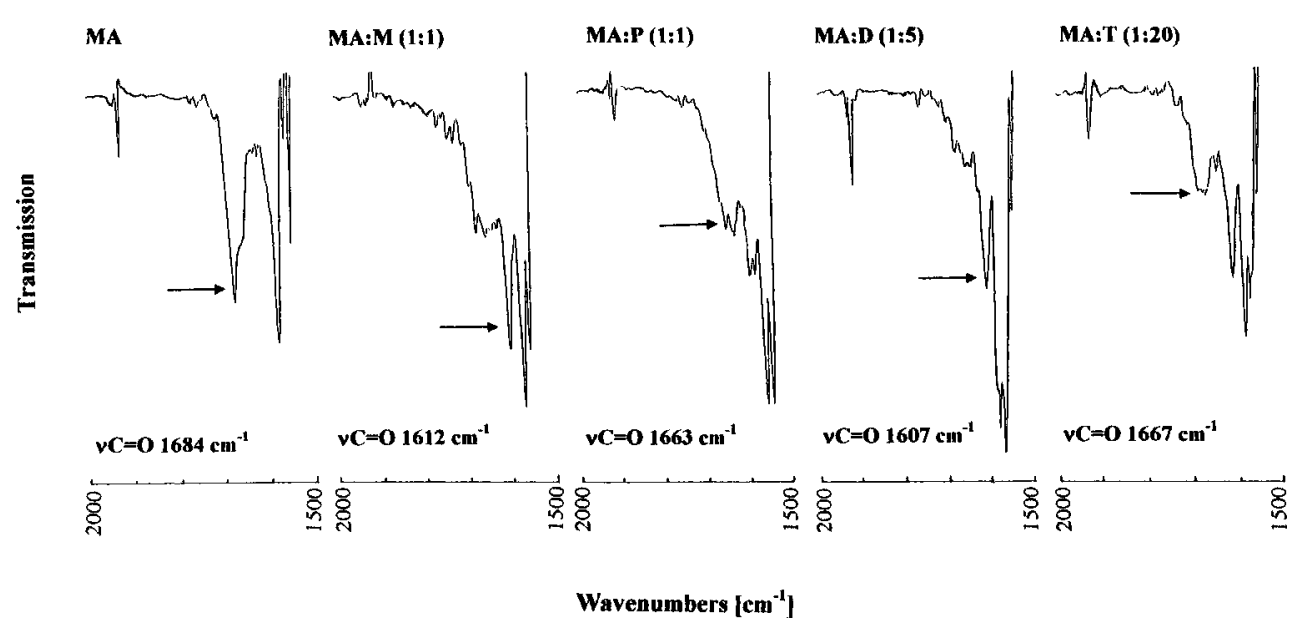

Fig. 5. The IR Spectra of MA and MA Mixed with Amines in Ethanol Solution

remained unchanged throughout the experiment. These results suggest that the enhancing effect of the TEI system is very dependent on the $\mathrm{T}$ concentration in the TEI system, and the permeation behavior of $\mathrm{E}$ is not influenced by the concentration of $\mathrm{T}$.

Fourier Transform Infrared Spectroscopy in Ethanol Solution To study the interaction between MA and T, the IR spectra of MA and MA with amines in E were determined (Fig. 5). The MA showed a strong narrow signal around $1682 \mathrm{~cm}^{-1}$, characteristic of the carbonyl stretching vibration. However, the carbonyl peak of MA with amines was shifted towards a lower wavenumber, indicating the carboxyl group of MA had been ionized. This interaction in E might reflect the interaction in EI system.

\section{DISCUSSION}

Many papers have shown that binary mixtures of polar (ethanol, isopropyl alcohol) and non-polar (oleic acid, IPM) enhancers results in synergistic enhancement of the skin transport of many drugs and these binary systems also cause reduced skin irritation. ${ }^{6,21)}$ In the present study, each drug flux in the EI system is greater than that with IPM. These findings agree well with the previous investigation in our laboratory. ${ }^{12)}$ Although it has not been well documented yet, this effect of the EI system is attributed to the synergic effect of the polar enhancer $\mathrm{E}$ and the non-polar enhancer IPM. ${ }^{22,23)}$ However, the effect of addition of T to the EI system, namely the TEI system, is confirmed for the first time by the present study. This system selectively enhances acidic drug permeation.

The flux of ketotifen fumarate in the TEI system significantly decreased compared with that in the EI system, although the flux of other basic drugs are almost unchanged in the TEI system. This decrease in skin permeation is probably a result from the formation of ketotifen free base in the TEI system. Since the basicity of $\mathrm{T}\left(\mathrm{p} K_{\mathrm{a}}=7.65\right)$ is stronger than ketotifen $\left(\mathrm{p} K_{\mathrm{a}}=6.73\right){ }^{24)}$ the addition of $\mathrm{T}$ to the EI system result in the formation of ketotifen free base. The ketotifen free base $\left(\log P_{\text {octanol/water }}=3.7\right)$ is a lipophilic drug, $\left.{ }^{25}\right)$ so the permeability using a lipophilic vehicles (TEI system) should be low, as it has been shown in the literature. ${ }^{26,27)}$

The enhancing effect of TEI system is not due to a reduc- tion in the barrier function of the stratum corneum; it is selective for acidic drugs; characteristic of the amine involved and correlates with its basicity; it is positively correlated with the concentration of $\mathrm{T}$ in the skin and in the donor vehicle. Combining these findings with the IR study, ion pair formation of MA and T is strongly suggested.

Further investigation is needed to clarify the relationship between ion pair formation and the enhancement effect.

\section{REFERENCES}

1) Samir M., Pharm. Res., 17, 1354-1359 (2000).

2) Charles S. A., Bozena B. M., PSTT., 3, 36-41 (2000).

3) Barrie C. F., Timothy M. M., J. Pharm. Sci., 88, 955-958 (1999).

4) Goldberg-Cettina M., Liu P., Nigtingale J., Kurihara-Bergstrom T., Int. J. Pharmaceut., 114, 237-245 (1995).

5) Hori M., Satoh S., Maibach H. I., "Percutaneous Absorption," ed. by Bronaugh R. L., Maibach H. I., Marcel Dekker, New York, 1989, pp. 197-211.

6) Sudhir R. G., Li L. L., Kim K. H., Int. J. Pharmaceut., 192, 159-172 (1999).

7) Morimoto Y., Sugibayashi K., Kobayashi D., Shoji H., Yamazaki J., Kimura M., Int. J. Pharmaceut., 91, 9-14 (1993).

8) Kobayashi D., Matsuzawa T., Sugibayashi, K., Morimoto Y., Kobayashi M., Kimura M., Biol. Pharm. Bull., 16, 254-258 (1993).

9) Sugibayashi K., Kobayashi D., Nakagaki E., Hatanaka T., Inouue N., Kusumi S., Kobayashi M., Kimura M., Morimoto Y., Int. J. Pharmaceut., 113, 189-197 (1995).

10) Nakamura H., Pongpaibul Y., Hayashi T., Sugibayashi K., Morimoto Y., Int. J. Pharmaceut., 141, 71-80 (1996).

11) Kobayashi Y., Nakamura H., Sugibayashi K., Morimoto Y., Int. J. Pharmaceut., 156, 153-162 (1997).

12) Nakamura H., Kobayashi Y., Sugibayashi K., Morimoto Y., Drug Del. Sys., 12, 101-106 (1997).

13) Moffat A. C., Jackson C. V., Moss M. S., Widdop B., "Phamaceuticals, Body Fluids and Post-Mortem Material," ed. by The Pharmaceutical Press, Second ed., London, 1986, pp. 533-534.

14) Okumura M., Sugibayashi K., Ogawa K., Morimoto Y., Chem. Pharm. Bull., 37, 1404-1406 (1989).

15) Hirai T., Matsumoto S., Kishi I., J. Chromatogr. B, 692, 375-388 (1997).

16) Dawodu O. F., Meisen A., J. Chromatogr., 629, 297-307 (1993).

17) "Handbook of Pharmaceutical Excipients," American Pharmaceutical Assosiation and The Pharmaceutical Society of Great Britain, 1986, pp. $334-335$.

18) Knaak J. B., Leung H. W., Busch Stott W. T. J., Bilsky J., Rev. Environ. Contam. Toxicol., 149, 1-86 (1997).

19) Müller-Decker K., Heinzelmann T., Fürstenberger G., Kecskes A., Lehmann W.-D., Marks F., Toxicol. Appl. Pharmacol., 153, 59-67 
(1998).

20) World health organization, "IAAC Monographs on the Evaluation of Carcinogenic Risks to Humans," Vol. 77, Lyon, 2000, pp. 381-401.

21) Cooper E. R., Merritt E. W., Smith R. L., J. Pharm. Sci., 74, 688-690 (1985).

22) Harada S., Takahashi Y., Nakagawa H., Yamashita F., Hashida M., Biol. Pharm. Bull., 23, 1224-1228 (2000).

23) Jin Y., Toeda C., Kawaguchi T., Seki T., Juni K., Drug Dev. Ind. Pharm., 22, 653-658 (1996).
24) Lee Y. L., Chiang C. H., Chen J. L., Drug Dev. Ind. Pharm., 20, 2965-2976 (1994).

25) Inoue K., Ogawa K., Suzuki Y., Okada J., Kusai A., Ikeda M., Nishimura K., Drug Dev. Ind. Pharm., 26, 45-53 (2000).

26) Roberts M. S., Walters K. A., "Dermal Absorption and Toxicity Assessment," ed. by Robert M. S., Walters K. A., Marcel Dekker, New York, 1998, pp. $1-42$.

27) Blank I. H., J. Invest. Dermatol., 43, 415-420 (1964). 